\title{
Summer plans
}

Published at www.cmaj.ca on Oct. 16

$\mathrm{E}$ very spring, medical students across the country ponder what to do over the summer.

Altruism?

Resumé building?

Relaxation?

Adventure?

All of the above?

Inevitably, hundreds of students choose to participate in global health learning opportunities in low-income countries. According to an Association of American Medical Colleges' survey, over $25 \%$ of American students participate in international experiences over the course of their training (www.aamc.org/data/gq/allschools reports 7/start.htm).

While much attention is given to the educational needs of the visiting student, increasingly, Canadian institutions are giving more consideration to the impact that will be made on local students and health care resources in the host country.

From September 2007 to December 2008, I became involved in a partnership between the University of Western Ontario and the National University of Rwanda, and found myself partnered with Edmond Baganizi, a Rwandan medical student who was also in his second year of studies.

I worked with Baganizi on study design and planning. My 'head-in-theclouds' idea of project design was critically complimented by his 'realities of Rwanda' approach to study implementation.

I arrived in Kigali last June, to a warm welcome from my new friend and colleague. It was the start of a summer in Rwanda that proved an amazingly rich learning experience, both academically and culturally.

I was able to live and work in an environment so different from my own

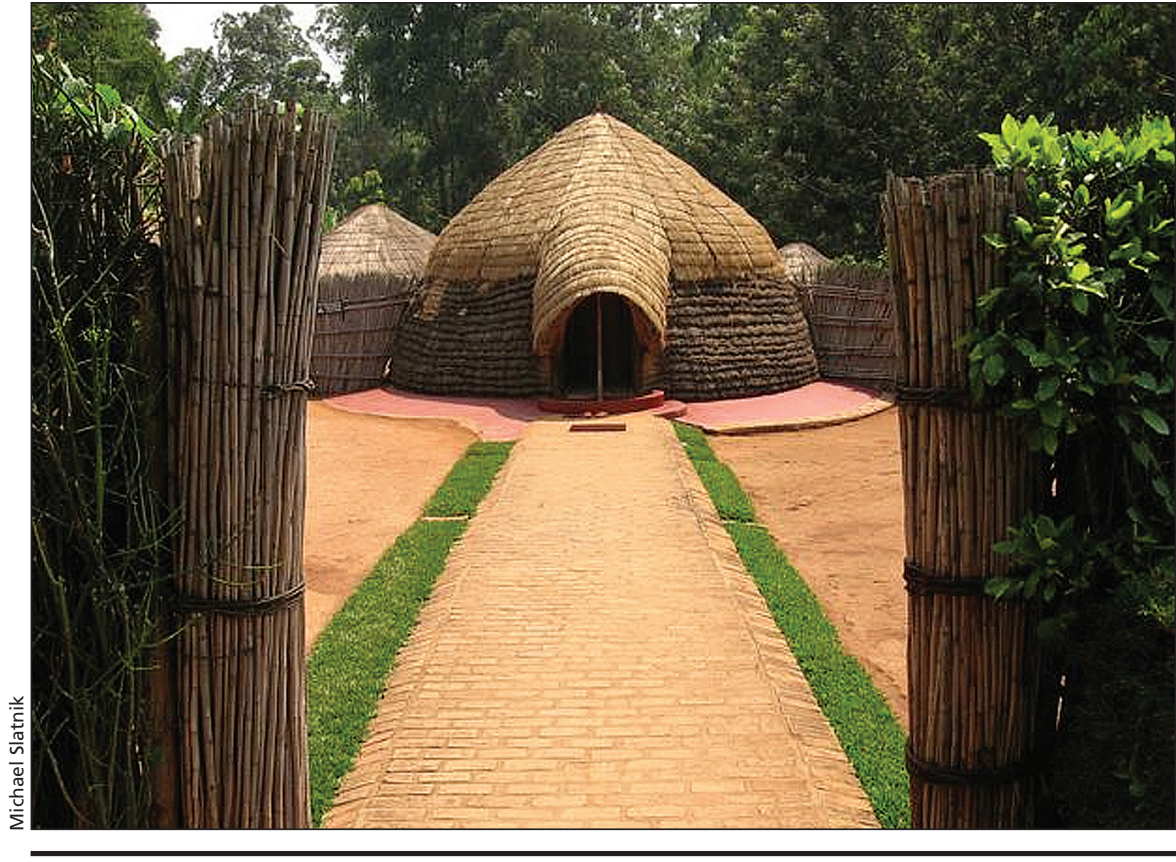

A traditional Rwandan hut.

and learn much about Rwanda and its wonderful people. I ate copious amounts of mélange (the local fare) and spent many evenings crunching data at Yuppy Yummie (the hospital cafeteria).

I couldn't think of a better way to have spent my summer.

Over the course of the summer, I benefited immensely in terms of personal growth, as well as academic and research experience. My Rwandan counterparts were equally involved in all aspects of project planning and implementation. Subsequently, both Baganizi and I were able to present our research findings at separate international meetings.

The data we ultimately gathered and presented to Rwandan clinicians, although useful, realistically may or may not result in improved health outcomes, or decreased morbidity and mortality from cardiovascular disease in Rwanda.

Yet, regardless of the eventual outcome, I am contented that we students benefited from the experience. Medical students working together can provide direct and indirect benefits to the communities they visit, as well as to each other. I hope that by encouraging contacts and partnership with local medical students abroad, while participating in international work, other Canadian medical students have as wonderful an experience. - Michael Slatnik, London, Ont.

DOI:10.1503/cmaj.109-3079

CMAJ invites contributions to "Dispatch from the medical front," in which physicians and other health care providers offer eyewitness glimpses of medical frontiers, whether defined by location or intervention. Submissions, which must run a maximum 700 words, should be forwarded to:wayne.kondro@cmaj.ca 